\title{
Mirabegron: first $\beta 3$ agonist in treatment of overactive bladder
}

\author{
Paramdeep Singh Gill", Nipunjot Grewal
}

Department of Pharmacology, Sri Guru Ram Das Institute of Medical sciences and Research, Amritsar, India

Received: 29 September 2012 Accepted: 30 September 2012

*Correspondence to:

Dr. Paramdeep Singh Gill,

E-mail: gilldocin@yahoo.co.in

\begin{abstract}
Mirabegron is the first and only $\beta 3$ agonist approved by US FDA in June 2012 for treatment of Overactive bladder with symptoms of urge incontinence, urgency and urinary frequency. It is the first oral $\mathrm{OAB}$ treatment with a distinct mechanism of action since the launch of anticholinergic agents 30 years ago. It causes relaxation of detrusor smooth muscle by its agonist action at $\beta 3$ receptors leading to increased storage capacity of bladder. It has been studied extensively in more than 10,000 individuals over 10 years.
\end{abstract}

Keywords: Overactive bladder, Anticholinergics, $\beta 3$ agonist

\section{INTRODUCTION}

Overactive bladder (OAB), as defined by the International Continence Society, is characterized by a symptom complex including urinary urgency with or without urge incontinence, usually associated with frequency and nocturia. The frequency is characterized by voiding eight or more times in a 24-hour period and nocturia comprises of awakening two or more times at night to void. ${ }^{1}$ Patients with overactive bladder tend to limit their participation in social activities and Nocturia is usually associated with sleep disruption, which may disrupt quality of life. The prevalence of $\mathrm{OAB}$ increases with age and is more common in women than men and in Asia; it's about $53.1 \% .^{2}$

In about $75 \%$, OAB symptoms are due to idiopathic detrusor activity (IDO); neurological disease, bladder outflow obstruction (BOO) intrinsic bladder pathology and other chronic pelvic floor disorders are implicated in the others.

The therapy is aimed at reducing the symptoms and improving the quality of life. The treatment comprises of both non-pharmacological and pharmacological treatment.

Non-pharmacological treatment comprises of behavioural therapy comprising of bladder retraining, pelvic floor strengthening exercises and fluid management. ${ }^{3}$

\section{PHARMACOLOGICAL TREATMENT}

Anticholinergics (Hyoscyamine, Oxybutynin, Propantheline, Tolterodine, Trospium) are the main stay of treatment for OAB. These act by relaxing the detrusor muscle by blocking the muscarinic receptors (M3 and M2) in bladder. These anticholinergic drugs produce some bothersome side effects like dry mouth, dry eyes, blurred vision, urinary retention and cognitive side effects which are especially unacceptable in elderly population. ${ }^{4}$

Alpha adrenergic antagonist like Alfuzosin, Doxazosin, Prazosin, Tamsulosin, terazosin are preferred in men with benign prostatic hypertrophy. ${ }^{5}$

Recently first of its class has been approved by FDA which is beta-3 adrenergic receptor agonist. Mirabegron is an agonist of the human beta-3 adrenergic receptor. It was approved by FDA in June 2012. It's first in its class i.e. selective beta-3 agonist, which is approved for OAB. It relaxes the detrusor smooth muscle during the storage phase of the urinary bladder fill-void cycle by activation of beta-3 AR which increases bladder capacity. ${ }^{6}$

It has a chiral centre ( $\mathrm{R}$ and $\mathrm{S})$, however it's developed as $\mathrm{R}$ enantiomer and there is no chiral inversion. The bioavailability is dose dependent, at $50 \mathrm{mg}$ dose it's about $35 \%$. Protein binding is about $71 \%$ and its terminal halflife is 50 hours. The metabolism is by various pathways such as dealkylation, oxidation, glucuronidation and hydrolysis; it's metabolized to about ten metabolites. The CYP involved is CYP3A4. The metabolites are excreted in urine and feces, however $25 \%$ is excreted unchanged in urine. It's a moderate CYP2D6 inhibitor; hence it increases systemic exposure of desipramine and metoprolol. Reduction of dose is required in severe renal impairment and moderate hepatic impairment. ${ }^{6}$

The recommended starting dose for Mirabegron is $25 \mathrm{mg}$ once daily with or without food. Mirabegron $25 \mathrm{mg}$ is 
effective within eight weeks; based on individual efficacy and tolerability, the dose may be increased to $50 \mathrm{mg}$ once daily. ${ }^{6}$

\section{CLINICAL TRIALS}

Mirabegron was studied in patients who were primarily Caucasian (94 percent) and female (72 percent) with a mean age of 59 years (range 18-95 years). The population included both naive patients who had not received prior antimuscarinic pharmacotherapy for $\mathrm{OAB}$ (48 percent) and those who had received prior antimuscarinic pharmacotherapy for OAB (52 percent). The approval of Mirabegron was based on safety and efficacy data from three placebo-controlled Phase 3 studies, in which treatment with Mirabegron $25 \mathrm{mg}$ and $50 \mathrm{mg}$ resulted in statistically significant improvement in efficacy parameters of incontinence episodes and number of urinations per 24 hours. $^{6}$

In treatment with Mirabegron $25 \mathrm{mg}$, incontinence episodes were reduced by 1.36 episodes from a baseline of 2.65, a statistically significant reduction of 0.40 vs. placebo in 12 weeks. The number of urinations was reduced by 1.65 urinations from a baseline of 11.68 , a statistically significant reduction of 0.47 vs. placebo in 12 weeks. $^{6}$

In treatment with Mirabegron $50 \mathrm{mg}$, incontinence episodes were reduced by 1.49 episodes from a baseline of 2.71 , a statistically significant reduction of 0.40 vs. placebo in 12 weeks. Number of urinations was reduced by 1.75 urinations from a baseline of 11.70 , a statistically significant reduction of 0.55 vs. placebo in 12 weeks. ${ }^{6}$

\section{ADVERSE EFFECTS}

Mirabegron was evaluated for safety in more than 2,700 patients in three, 12-week Phase 3 double-blind, placebocontrolled studies and in a one year, randomized fixed dose, active-controlled study in patients with OAB. The most commonly reported adverse reactions (greater than 2 percent of Mirabegron patients and greater than placebo) were hypertension, nasopharyngitis, urinary tract infection and headache. ${ }^{6}$

Periodic blood pressure monitoring is recommended especially in patients having hypertension. Urinary retention in patients with bladder outlet obstruction and in patients taking antimuscarinic medications for the treatment of overactive bladder has been reported in post marketing experience in patients taking mirabegron. It is a pregnancy category $\mathrm{C}$ drug in which there are no adequate and well controlled studies using mirabegron in pregnant women. The safety and effectiveness of this drug in pediatric patients have not been established.

\section{PLACE IN THERAPY}

Mirabegron seems to be a promising option in OAB patients, as it is devoid of side effects which are associated with standard treatment. Though it has yet to make its mark, as it has been recently launched.

\section{REFERENCES}

1. Abrams P, Cardozo L, Fall M, Griffiths D, Rosier P, Ulmsten U, et al. The standardisation of terminology of lower urinary tract function: report from the Standardisation Sub-committee of the International Continence Society. Neurourol Urodyn 2002;21:167-78.

2. Lapitan MC, Chye PL. The epidemiology of overactive bladder among females in Asia: a questionnaire survey. Int Urogynecol J Pelvic Floor Dysfunct 2001;12:226-31.

3. Fantl JA, Wyman JF, McClish DK, et al. Efficacy of bladder training in older women with urinary incontinence. JAMA 1991;265:609-13.

4. Herbison P, Hay-Smith J, Ellis G, Moore $\mathrm{K}$. Effectiveness of anticholinergic drugs compared with placebo in the treatment of overactive bladder: systematic review. BMJ 2003;326:841-4.

5. Thomas AW, Abrams P. Lower urinary tract symptoms, benign prostatic obstruction and the overactive bladder. BJU Int 2000;85 Suppl 3:57-68.

6. Myrbetriq (Mirabegron) prescribing information. Available http://www.us.astellas.com/docs/myrbetriq-fullpi.pdf. Accessed 19 September 2012. 